\title{
A FUNCTIONAL INTERPRETATION OF LOCATIVE PREFIXES IN ENGLISH
}

\author{
Eulalia Sosa AcEvedo \\ University of La Laguna
}

\begin{abstract}
This paper explores the adequacy of the Functional Lexematic Model (FLM) for the description and interpretation of bound lexical units with a special insight into the cognitive mechanisms underlying locative prefixation in English. The basic claim here will be that the FLM constitutes an adequate framework for the treatment of morphology as a dynamic rather than as a static encapsulated phenomenon in language and that, with the incorporation of a cognitive axis, the FLM facilitates access to the underlying properties and the structure of the lexicon.
\end{abstract}

\section{INTRODUCTION ${ }^{1}$}

Much of the work done in linguistics during the last decades of the twentieth century was devoted to the study of the lexicon. Important contributions like Aronoff's (1985) or Spencer's (1988) within the framework of Transformational Generative Grammar depart from both lexicist and syntacticist views of word formation and mark a significant turn in the course of morphology in the eighties and nineties. Inspired by the same course, Dik's Functional Grammar (1997) contributes to reinforce the view that the lexicon constitutes a central, rather than a subsidiary, component of the grammar of languages.

1. This paper is part of two research projects: "Gramática y mecanismos de interficie de las clases léxicas verbales del inglés antiguo" funded by the Spanish Ministry of Science and Technology (Ref: BFF 2002-00639), and "Mecanismos de interficie en los procesos de prefijación locativa en inglés", funded by the University of La Laguna (Code: 1802640402). Research work has also been carried out in the Instituto de Lingüística Andrés Bello, Universidad de La Laguna. 
As far as derivation is concerned, the Model of Functional Grammar (Henceforth FG) propounds crucial mechanisms and principles. Particularly relevant are Predicate Formation and Stepwise Lexical Decomposition. No methodological framework, however, has been designed for the performance of these mechanisms within the model.

In this paper we will precisely lay out the methodological bases of the FLM which seems to exhibit an extremely high degree of adequacy for lexical analysis in general and for the appraisal of the properties that govern the derived vocabulary in particular.

\section{WORD-FORMATION AND PREDICATE FORMATION RULES}

Though FG avoids transformations, Dik claims that the component of Predicate Formation " [...] does require transformations of a sort" (1997, Part I: 21). Predicate Formation Rules (Henceforth PFRs) serve to derive simple forms like walk-walker or white-whitened (E.g: The paper whitened from The paper was white), as well as more complex structures like This typewriter writes nicely from John writes on this typewriter (1997, Part I: 220,349). As De Groot (1987:7) states, therefore, a PFR "does not necessarily involve any morphology", and hence, the representation of morphological processes by means of transformations does not guarantee any adequate distinction between word formation associated to syntactic processes (E.g.: white $_{A d j}$-whitened ${ }_{V}$ in The paper whitened) and syntactically independent processes of lexicogenesis, derivation proper (E.g: man-foreman, walk-walker, etc.). In addition, evidence provided by Cortés (1997a, 1997b and 1997c) about nominalizing suffixes and by Sosa (2004a) about locative prefixation in English indicates that PFRs are not sufficiently powerful to account for the factors that most fundamentally determine the properties and the structure of the derived lexicon. We may certainly propose a PFR for derived forms like, for instance, superman, superstar and superstructure. By adapting the representation of non-verbal predicates from Hengeveld (1992) and Mackenzie (1986), this rule can be formulated as follows:

(1)

$$
\begin{aligned}
& \text { input: } \operatorname{pred}_{\mathrm{p}}\left(\mathrm{x}_{1}\right)_{\mathrm{Loc}}\left(\mathrm{x}_{2}\right) \varnothing \\
& \text { output: } \operatorname{OVER}_{\mathrm{p}}\left(\mathrm{x}_{1}: \operatorname{man}\right)_{\mathrm{Loc}}\left(\mathrm{x}_{2}\right) \varnothing
\end{aligned}
$$

2. The methodological framework of the FLM was first designed by Martín Mingorance (1984, 1985a, 1985b, 1987a, 1987b, 1987c, 1990). For the configuration of the Word Formation Component within the FLM, see Faber (1991). Faber and Mairal (1994, 1997a, 1997b, 1998, 1999) and Mairal (1999). Among others, the following publications present relevant work on the treatment of derivation within this model: Cortés (1996, 1997a, 1997b, 1997c), Sosa (2000, 2004a, 2004b). 
where:

$\mathbf{x}_{\mathbf{1}}$ and $\mathbf{x}_{\mathbf{2}}$ represent spatio-temporal entities;

$\mathbf{p}$ refers to the prepositional category of the predicate;

Loc refers to the semantic function Location;

$\varnothing$ is assigned to the entity involved in a state (E.g. location)

meaning: 'the entity designated by $\mathrm{x}_{2}$ is presented as taking a higher position with respect to $\mathrm{x}_{1}, \mathrm{x}_{1}$ and $\mathrm{x}_{2}$ being entities of the same typology ('man'...).

E.g: superman, superstar, super-structure: 'man OVER man, star OVER star...'

The input specifies a two-place prepositional predicate ( pred $_{\text {preposition: }}$ : OVER $_{\text {preposition }}$ ) that embodies the meaning of the prefix (see Mackenzie 1986). The first argument $\left(\mathrm{x}_{1}\right)$ realises the semantic function Location (Loc: 'place, position') whereas the second argument ( $\mathrm{x}_{2}$ : 'entity subject to location') is assigned Zero semantic function (see Dik 1997, Part I: Chapter 5). Both $\mathrm{x}_{1}$ and $\mathrm{x}_{2}$ prototypically designate the same type of first-order (spatio-temporal) entity (see Dik 1997, Part I: 137). In the ouput predicate, these variables are replaced with the corresponding lexical items: OVER ${ }_{\mathrm{p}}\left(\mathrm{x}_{1} \text { :man/star/structure }\right)_{\text {Loc }}\left(\mathrm{x}_{2}\right.$ : $\mathrm{man} /$ star/structure), expressing that 'the entity $\mathrm{x}_{2}$ is presented as taking a higher position with respect to $\mathrm{x}_{1}$ '. Since $\mathrm{x}_{1}$ and $\mathrm{x}_{2}$ are entities of the same typology, the output reads as follows: 'man OVER/SUPERIOR TO man, star OVER/SUPERIOR TO star, structure OVER/SUPERIOR TO structure...'

The rule in (1), however, does not capture essential features of the derived forms that have a direct impact on the structure of the lexicon:

(i) It does not prevent the formation of units like ?super-smoker, "supersee, etc.

(ii) No specifications are provided for the restriction of forms like * bypersuper-market in favour of supermarket and bypermarket, or like *fore-active in favour of byper-active.

(iii) Conversely, this rule does not account for the formation of ad hoc expressions like superfather, super-school, super-soul... formations that are not registered in the corpus and lexicographical records but that obviously constitute part of the speaker's lexical competence (see Faber and Mairal Usón 1999).

(iv) It does not capture the restrictions that motivate related combinations like super/ultrasonic; super/hypermarket... but not like super/"ultraman 
In general, it seems that PFRs are not sufficiently restrictive and thus they miss relevant regularities of the derived vocabulary. Rule (1) basically expresses that there is a consistent semantic relation of superiority underlying the output units (E.g: 'man OVER man', 'star OVER star...'). But, how can we account for the fact that both foreman and superman may be outputs of rule (1)? Do foreman, superman, bypermarket, ultraviolet, etc. characterise superiority in the same way?. As Martin Mingorance (1990: 232-233) observes, even though the model of FG propounds the principle of Stepwise Lexical Decomposition as a means to approach semantic relations within the lexicon (see Dik 1997, Part I: 99-101), it does not provide any appropriate methodology to access lexical structures:

[...] it is somewhat paradoxical that within FG no coherent methodology has been devised for the onomasiological structuring of the lexicon which would make possible its organization in lexical fields and, consequently, the stepwise lexical decomposition of groups of lexemes of each field.

We will propose the FLM as a more adequate framework to account for the structure of and the interrelations within the derived lexicon. In so doing, we will confine ourselves to the analysis of prototypical formations of Anteriority and Superiority since we believe they clearly illustrate the general structure and the mechanisms that operate in the organization of the locative derived vocabulary. Since this analysis is, however, part of a broader corpus-based research on locative prefixation, we first introduce some general aspects related to the selection of the corpus in the next section.

\section{THE SELECTION OF THE CORPUS}

From a functional-lexematic perspective, the essential criterion for the selection of derived units is that derived formations must be semantically-motivated units, that is to say, they must constitute combinations of morphemes or composites (see Marchand 1969: 11-12). This basically means that forms like precede, antecedent, bypocrite, etc. dot not represent instances of derivation proper, as opposed to, for instance, pre-conceive, anteroom, bypotension, etc., since the particles -cede, -cedent and -crite are not morphemic, they do not constitute form-meaning pairings (cf. conceive, room and tension).

By applying this criterion, the first step in extracting the data from the corpus has been to collect prefixed formations from The Tagged LOB Corpus (see Johansson et al. 1986) and The Collins COBUILD English Dictionary (see Sinclair 1995), the latter serving also as reference for meaning check. ${ }^{3}$ The number of instances 
collected for each locative prefix is presented in Table 1 below where $L O B$ samples are given within brackets while unbracketed numbers indicate the total amount of samples (both $L O B$ and COBUILD). In a second step, sampled prefixed formations have been grouped into eight lexical classes on the basis of the prototypical meaning they exhibit: Anteriority, Posteriority, Centrality, Superiority, Inferiority, Exteriority, Opposition and Motion. In Section 4 we present the main principles and criteria that determine the organization of lexical units into lexical classes within $F L M$. The full body of data and the general results regarding each of these lexical classes can be found in Sosa (2004a).

Finally, it seems worth noting at this point that prefixed formations appear hyphenated and/or in full form (see Table 1). Sosa (2004b) observes that hyphenation systematically correlates with the degree of lexicalisation of the prefixed units. Prototypically, non-hyphenated formations show a higher degree of lexicalisation as compared with full forms. The coexistence of both possibilities in the same unit (E.g. foreroom; fore-room) is generally interpreted as lexicalisation in progress, but it seems to be also determined by socio-cultural conditions associated to the different varieties of English.

\begin{tabular}{|c|c|c|c|}
\hline Domain & Prefixes & $\begin{array}{l}\text { Prototypical } \\
\text { Formations }\end{array}$ & $\begin{array}{r}\text { Number of } \\
\text { formations } \\
\text { registered }\end{array}$ \\
\hline \multirow[t]{3}{*}{ Anteriority } & Ante\# & anteroom & 4 \\
\hline & Fore\# & forecourt & 40 \\
\hline & Pre\# & predeterminer & $73 \mathrm{Lob}^{*}$ (31) \\
\hline Posteriority & Post\# & postdeterminer & $34 \operatorname{Lob}(15)$ \\
\hline \multirow[t]{3}{*}{ Centrality } & Inter\# & inter-parliamentary, & 75 Lob (32) \\
\hline & Intra\# & intracontinental & $3 \operatorname{Lob}(1)$ \\
\hline & Mid\# & mid-section, & $36 \mathrm{Lob}$ (29) \\
\hline \multirow[t]{6}{*}{ Superiority } & Meta\# & metaphysical & $4 \operatorname{Lob}(1)$ \\
\hline & Para\# & parapsychology & $4 \operatorname{Lob}(2)$ \\
\hline & Super\# & superman & $25 \operatorname{Lob}(23)$ \\
\hline & Hyper\# & hyper-sophisticated & $5 \operatorname{Lob}(2)$ \\
\hline & Ultra\# & ultra-sophisticated & $6 \operatorname{Lob}(4)$ \\
\hline & Sur\# & surmount & $3 \operatorname{Lob}(2)$ \\
\hline
\end{tabular}

3. Formations not registered in The Collins COBUILD have been checked at other dictionaries: The Longman Dictionary of Contemporary English (1995) and The Oxford English Dictionary (1933, 1989). 


\begin{tabular}{r|c|c|c}
\multirow{2}{*}{ Inferiority } & Hypo $\#$ & hypoallergenic & $3 \operatorname{Lob}(1)$ \\
\cline { 2 - 4 } & Sub\# & subculture & $48 \operatorname{Lob}(35)$ \\
\hline \multirow{2}{*}{ Exteriority } & Ex\# & exorbitant & $22 \operatorname{Lob}(20)$ \\
\cline { 2 - 4 } & Extra\# & extraordinary & $8 \operatorname{Lob}(4)$ \\
\hline Motion & Anti \# & antibody & $47 \operatorname{Lob}(39)$ \\
\cline { 2 - 4 } & Counter\# & counter-espionage & $29 \operatorname{Lob}(24)$ \\
\hline
\end{tabular}

Table1: prototypical lexical classes for sampled locative formations.

\section{THE LEXICON IN THE FLM: THE COGNITIVE AXIS AND THE SCHEMATA}

One of the major obstacles that the linguistic models of the seventies and eighties are faced with concerns the fact that word formation is considered to be a static phenomenon, that is to say a phenomenon generally associated to the syntactic component. ${ }^{4}$ In contrast, the data provided by Cortés (1997c) and by Sosa (2004a) reveal that derivation is a dynamic process (i.e. a complex process simultaneously restricted at all the levels of linguistic description and organization, namely phonology, morphology, semantics, pragmatics and syntax), and that such restrictions operate systematically across the derived lexicon. Furthermore, from a functional perspective, the static view of the lexicon is in conflict with the ordinary communicative strategies the speakers make use of, like metaphors, presuppositions, pragmatic factors, etc. As Rosch (1978) claims, the categorization of the reality around us is not a closed and discrete capacity and the way the physical experience is conceptualised depending on a variety of factors (movement of the body, social environment, perception...) is projected onto lexical properties. In this respect, Faber and Mairal (1994: 196) contend, "...] one can arrive at an inventory of conceptual categories and their interrelationships through the structure of language itself, as a reflection of our understanding of reality, or our way of having the world".

Much in accordance with this view, the FLM incorporates a cognitive perspective (the cognitive axis) and propounds a multi-level structure for the lexicon in which cognitive mechanisms are regarded as an essential factor (see Martín Mingorance 1985b, 1987a, 1987b, 1990):

4. For an overview of the most salient lexicist and syntacticist approaches to word formation, see Cortés (1997b,c). 
(4)

(i) The lexicon constitutes a structure in the Coserian sense (see Coseriu 1986: 212) and comprises at least four interrelated levels or axes: paradigmatic level, syntagmatic level, pragmatic level and cognitive level.

(ii) The meaning or definition of lexical units lies at the convergence of information provided by these four levels or axes. Derivational schemata constitute formal representations of this lexical content.

(iii) The lexicon exhibits a hierarchical onomasiological, rather than semasiological, organization of lexemes. They are arranged in domains and sub-domains (lexical fields), from the most basic to the most complex. The full body of this hierarchy constitutes a macrostructure, the general layout of which is given below (see Faber and Mairal Usón 1994, 1999):

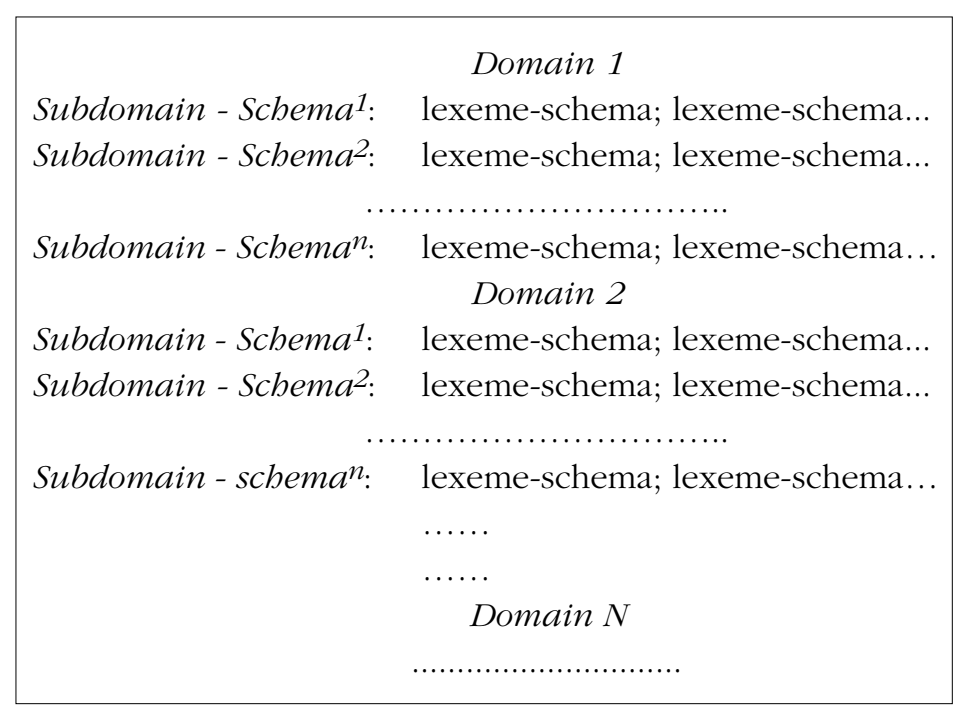

Macrostructure of the lexicon.

(iv) From a cognitive perspective, a derivational schema constitutes a cognitive pattern, a maximal projection of a conceptual content. Each domain and subdomain, as well as the lexemes they comprise, is therefore associated to a specific cognitive schema (see Faber y Mairal 1999: 217 ff.): 
DOMAIN: Superiority

Lexemes Conceptual content: " $\mathrm{x}_{2}$ OVER $\mathrm{x}_{1}$ " Cognitive schema

$\begin{array}{lcc}\text { Superman } & \text { 'man OVER man' } & \mathrm{x}_{2} \\ \text { Superstar } & \text { 'star OVER star' } & \bigsqcup_{\text {OVER }} \\ \text { Super-ego } & \text { 'ego OVER ego' } & \mathrm{x}_{1}\end{array}$

The principles outlined above roughly establish that, from a functionallexematic perspective, information from all the linguistic levels projects onto the derived units, and that derivational schemata constitute appropriate representations of such projections. In the following sections, we will specifically lay the emphasis on how lexeme schemata embody the paradigmatic, the syntagmatic and the semantic-cognitive levels, and how the information they provide ultimately shapes the macrostructure of the lexicon.

\subsection{The SYNTAgmatic AND THE PARADIGMATIC STRUCTURE OF LOCATIVE DERIVED UNITS}

The syntagmatic properties underlying prefixed units are represented by means of prepositional schemata, prepositional predications like, for instance, $\left[\left(\operatorname{BEFORE}_{\mathrm{P}}\left(\mathrm{x}_{1} \text { :room }\right)_{\text {Ref }}\right)_{\text {Locus }}\left(\mathrm{x}_{2} \text { : room }\right)_{\text {Lcdum }}\right]_{\text {STATE }}$ for foreroom with the meaning ' $\operatorname{room}_{\mathrm{x} 2}$ BEFORE room $_{\mathrm{x} 1}$ ' and where:

(i) the variables $x_{1}$ and $x_{2}$ represent entities, and $p$ specifies the grammatical category of the predicate BEFORE as preposition (see Mackenzie 1992).

(ii) the labels Ref (Referent), Lcdum (Locandum) and Locus represent semantic functions. Locative relations involve the participation of three entities that perform the semantic functions Locandum (the entity that is subject to location, E.g. $\mathrm{x}_{2}$ : room), Referent (the entity with respect to which the Lcdum is placed, E.g. $\mathrm{x}_{1}$ : room) and Locus (the entity designating the position the Lcdum takes, E.g. before, at the front of... $\mathrm{x}_{2}$ : room).

(iii) STATE indicates that the predication designates a non-dynamic, noncontrolled state of affairs (see Dik 1997, Part I: 105 ff): 'room BEFORE room', 'man OVER man'... 
Following Lakoff and Johnson (1980:35 ff), we assume that such state relations constitute part-whole, metonymic conceptualisations in which a part (E.g. $\mathrm{x}_{2}$ : room $_{\text {Lcdum }}$ ) of an entity as a whole (E.g. an architectural setting) is presented as taking a specific position ([before room Ref $_{\text {Locus }}$ ).

Interestingly enough, metonymic relations of this sort seem to be ubiquitous across the locative derived lexicon and motivate the rise of paradigms (domains or lexical fields), as specified in (4) above (paradigmatic structure). For instance, formations with the prefix fore\# (E.g. fore-room, forefinger, forefoot, foreleg, forename, fore-stress, etc.) share syntagmatic and paradigmatic features with other prefixes (E.g: anteroom, pre-determiner...). They all conceptualise the basic relation ' $\mathrm{x}_{2}$ BEFORE $\mathrm{x}_{1}$ ' and they therefore constitute members of the same domain. Much in the same way, superman, hypermarket, ultraviolet, exorbitant, etc. designate ' $\mathrm{x}_{2}$ OVER/ABOVE/BEYOND ... $\mathrm{x}_{1}$ '. All of these formations belong in the domain Superiority, even though, as we shall show in Section 5, each prefix instantiates specific degrees of superiority:

\section{SYNTAGMATIC STRUCTURE:}

Anteriority

Superiority

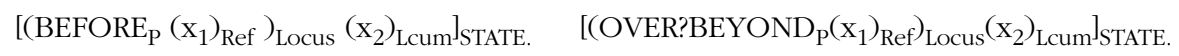

\section{PARADIGMATIC STRUCTURE:}

Anteriority

foreroom: 'room BEFORE room

forefinger: 'finger BEFORE/first finger

predeterminer: 'determiner BEFORE determiner

\section{Superiority}

superman: 'man OVER man'

bypermarket: 'market OVER market'

ultraviolet: 'violet OVER/BEYOND market'

\subsection{The SEMANTIC-COGNITIVE MOtIVATIONS OF LOCATION: THE EXPERIENTIAL ACCOUNT}

One of the most relevant properties of the lexicon is that the formations that belong in the same domain appear in hierarchical (onomasiological) order, from the most basic or lowest level to the most complex or highest level: 
(7)

\section{PARADIGMATIC STRUCTURE:}

foreroom 'room BEFORE room'

forefinger 'finger BEFORE fingers'

forefoot 'foot BEFORE feet'

forestress 'stress BEFORE stress'

foredeck 'deck BEFORE/ON THE FRONT OF deck'

forehead 'area BEFORE/ON THE FRONT OF head'

foreman: 'man BEFORE man'

foresee: 'see BEFORE see'

Two basic factors seem to determine this ordering. First, the typology of the entities, that is to say, the way in which the entities are conceptualised as mental constructs (see Dik 1997, Part I: 137 and Svorou 1993: 5). By incorporating Dik's typology of entities, derivational schemata distinguish first-order entities $\mathrm{x}_{1}$ and $\mathrm{x}_{2}$ (E.g: room in foreroom) that prototypically designate more basic conceptualisations from second-order entities $\mathrm{e}_{1}$ and $\mathrm{e}_{2}$ (E.g.: see in foresee) that conceptualise more complex relations: ${ }^{5}$

(8)

$$
\begin{aligned}
& \text { foreroom: }\left[\left(\operatorname{BEFORE}_{\mathrm{P}}\left(\mathrm{x}_{1}: \text { room }\right)_{\text {Ref }}\right)_{\text {Locus }}\left(\mathrm{x}_{2}: \text { room }\right)_{\text {Lcum }}\right]_{\text {STATE }} \\
& \text { foresee: }\left[\left(\operatorname{BEFORE}_{\mathrm{P}}\left(\mathrm{e}_{1}: \text { see }\right)_{\text {Ref }}\right)_{\text {Locus }}\left(\mathrm{e}_{2}: \text { see }\right)_{\text {Lcum }}\right]_{\text {STATE }}
\end{aligned}
$$

The second relevant factor concerns the semantic properties that characterise the entities. Following the classification of high-level or HPRIM and lower-level or LPRIM features established by Aarts y Calbert (1979: 18), the semantic contour of each entity is specified by means of features of the form [+Shape, +Dimensional]. ${ }^{6}$ Those entities characterized as [-Shape] (with no physical contour) or as [-Artifact]

5. Entities are classified into four main orders on the basis of the typology of entities proposed by Dik (1997, Part I: 137). First-order entities designate entities that can be located in space and time. Second-order entities designate states of affairs.

6. It seems worth comment that other means of semantic description and representation may be likewise compatible with this framework. Particularly interesting seem to be Pustejovsky's (1998) QUALIA Structures. 
(naturally created entity) are interpreted as conceptually more complex (notional) than those specified as [+Shape] (spatio-temporal entities) or [+Artifact] (manufactured, not naturally formed object): ${ }^{7}$

(9)

$$
\begin{aligned}
& \text { foreroom: }\left[\left(\operatorname{BEFORE}_{\mathrm{P}}\left(\mathrm{x}_{1}: \operatorname{room}<[+\mathbf{S h},+\mathbf{A r t}]>\right)_{\text {Ref }}\right)_{\text {Locus }}\left(\mathrm{x}_{2}: \operatorname{room}<[+\mathbf{S h},+\mathbf{A r t}]>\right)_{\text {Lcum }}\right]_{\text {STATE }} \\
& \text { forestress: }\left[\left(\mathrm{BEFORE}_{\mathrm{P}}\left(\mathrm{x}_{1}: \text { Stress }<[\text {-Sh, } \text {-Art }]>\right)_{\text {Ref }}\right)_{\text {Locus }}\left(\mathrm{x}_{2}: \text { stress }<[-\mathbf{S h},- \text {-Art }]>\right)_{\text {Lcum }}\right]_{\text {STATE }}
\end{aligned}
$$

It should be noted that both the typology of entities and the semantic features constitute semantic-cognitive restrictions rather than abstract properties of the linguistic units. Within the approach taken here, this means that cognitive and experiential aspects play a fundamental role in the structuring of lexical meaning (see Lakoff and Johnson 1980: 77 ff). Thus, for instance, we will claim in Section 6 that, though formations like foreroom and foreman both entail first-order entities (room and man respectively), man is not conceptualised as a spatio-temporal entity (i.e. a physical entity: 'man physically BEFORE man'), but rather as a conceptual entity involved in a hierarchically determined social grouping which entails 'man who is SUPERIOR TO other men'. This fact explains why foreman appears at a higher level, notional level, in (7) above, as opposed to foreroom, forefinger, etc. that represent spatio-temporal, physical conceptualisations (see Svorou 1993: 5 ff.). To illustrate this in more detail, let us sketch out how experiential ontological factors such as Number, Physicalness, Dimensionality and Perspective motivate the existence of different levels of conceptual complexity within the domain Spatial Anteriority.

\section{NUMBER}

The formations foreleg, forefinger and forefoot designate a part-whole relation between a definite number, not necessarily two, of first-order entities. The Referent designates 'set of first-order entities' (two or four legs, feet, parts, etc.) and it is the partition one-of-the-legs/feet/parts that is foregrounded here rather than the spatial contiguity of two entities (cf. foreroom: 'room BEFORE/SIDE TO SIDE WITH room'). Variation in the number of entities, therefore, seems to evoke different spatial conceptualisations, one more basic in which two entities are categorised as contiguous (E.g: foreroom), the other more complex in which one entity contrasts with a group of related entities (forefinger, forefoot, etc.). In the

\footnotetext{
7. As registered in the COBUILD ( $\neg$ stress), stress designates 'emphatic pronunciation of a word or part of a word'.
} 
light of this distinction we propose a subdivision of the domain Spatial Anteriority into two subdomains: first, Anteriority $\rightarrow$ Contact (E.g. foreroom) and second, Anteriority $\rightarrow$ Partition (E.g. forefinger). The operator $d N$ (definite number) in the schemata below captures such distinctions of number: ${ }^{8}$

(10)

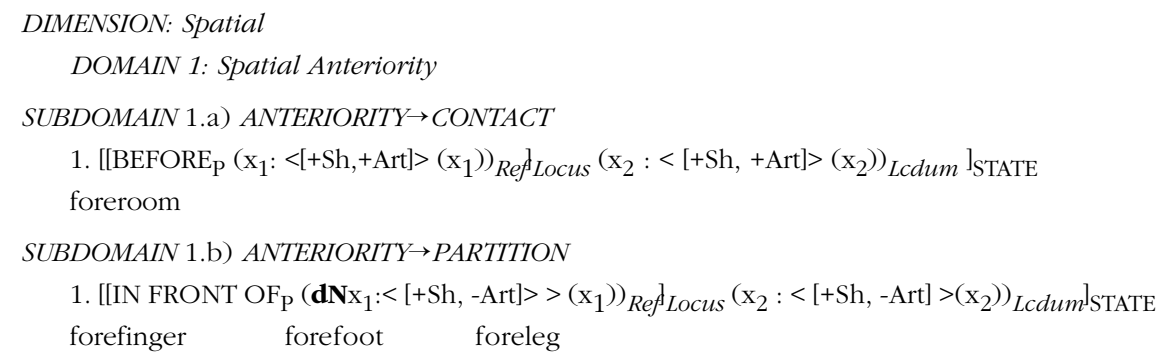

\section{Physicalness}

The participant entities in the formations forename and forestress are characterised as non-physical. The interpretation 'non-physical object BEFORE non-physical object' does not satisfy the spatial analysis suggested in the above examples since, prototypically, only physical objects can be placed side by side with other objects (cf. room, leg vs. name, stress). Within the subdomain Anteriority $\rightarrow$ Partition, therefore, the schemata 1 and 2 represented below, distinguish formations that, on the one hand, share properties of PARTITION rather than of mere CONTIGUITY and, on the other hand, show different semantic properties with respect to the higher-level restriction of Physicalness ([+Sh,-Art]: 'non-artifact with shape' vs. [-Sh,-Art]: 'non-artifact with no shape'):

(11)

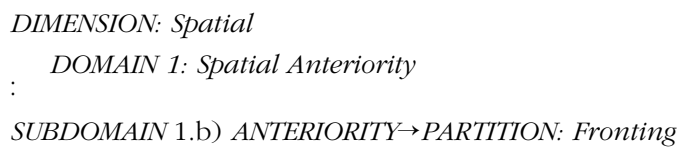

8. Operators constitute optional grammatical means that do not affect the internal structure of the predication (see Dik 1997, Part I: 138). 


\section{DiMENSIONALITY}

Dimensionality accounts for the fact that objects may be conceptualised as onedimensional, two-dimensional or three-dimensional entities in an increasing degree of perceptual complexity. While all the preceding patterns categorise objects as unitary one-dimensional entities (room, finger, etc.), the derived form fore-deck characterises the Referent as a two-dimensional entity (deck as a surface), whereas forebead categorises the Referent as a three-dimensional entity (bead). Dimensionality thus emerges as a high-level restriction over the categorisation of unitary objects. In the respective schemata of these formations, distinctions of Dimensionality are expressed by means of the prepositional hyponym ON (surface ON the front part of $d e c k .$. ) as opposed to the hyperonym IN/AT THE FRONT OF that characterizes basic formations (cf. forefinger, foreleg, etc.):

$$
\begin{aligned}
& \text { DIMENSION: Spatial } \\
& \text { DOMAIN 1: Spatial Anteriority } \\
& \text { SUBDOMAIN 1.b) ANTERIORITY } \rightarrow \text { PARTITION: Fronting }
\end{aligned}
$$

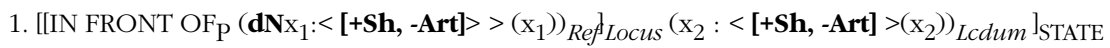

$$
\begin{aligned}
& \text { forefinger forefoot foreleg }
\end{aligned}
$$

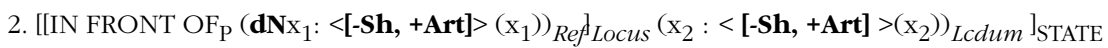

$$
\begin{aligned}
& \text { forename forestress }
\end{aligned}
$$

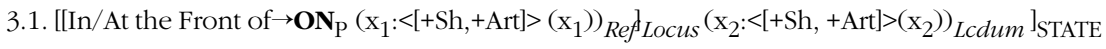

$$
\begin{aligned}
& \text { fore-gallows fore-loader fore-deck }
\end{aligned}
$$

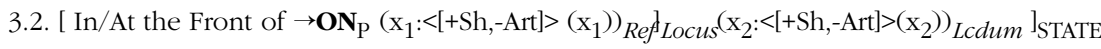

Derivational Schemata affected by dimensionality within Anteriority $\rightarrow$ Partition

\section{PERSPECTIVE}

Closely bound to Dimensionality, Perspective builds on the fact that physical objects are asymmetrical and show exterior and external regions (see Svorou 1993:

9. The exterior region of the entity is usually marked by its conceptual shape or outward contour (E.g. the shape of one finger with respect to the other fingers). The external region may be defined as the conceptual space in between various exterior regions (E.g. the space in between the fingers). 
16). They may be interpreted as individual regions or conceptualised in terms of sub-regions that stand in contrast, either on a borizontal axis (front/back, left/right) or on a vertical axis (top/bottom, up/down). The underlying patterns representing foredeck, forelock, forehead and foreskin categorise a specific sub-part (the front) of the Referent which, together with properties associated to dimensionality, subsume all these formations under the sub-subdomain Fronting (see (11) above). The units foregallows, fore-loader and foredeck ${ }^{10}$ designate 'physical object ON the FRONT PART of the surface of a larger object (ship, loader...)' whereas, in forehead, the Referent categorises 'the FRONT surface of the head', of a three-dimensional entity, and foreskin designates 'area, surface of an entity (body element) ON/AROUND FRONT OF body-part'.

The entire structure of the spatial domain thus seems to develop progressively from, first, prototypical spatial relations between objects conceptualised as unitary entities, second, the more complex specification of the number of entities and their intrinsic properties, and finally, the sub-parts of the entities, altogether ontological factors of experience. The gradual complexity that this hierarchy of spatial configurations involves may be illustrated as follows:

10. Lexicographical sources do not register the forms fore-gallows and fore-loader. Below we quote the selections collected from the LOB corpus and from which we have inferred the meaning 'gallows, loader $\mathrm{ON}$ the front part of a two-dimensional object (ship, farm vehicle like a tractor respectively).

$23.395 \mathrm{c}: \backslash$ lobtagh $\backslash$ lobt-n3.h 77. [...] other craft lay for their lives in the hurricane wind and giant seas. The ton-weight outer board of the net had ripped free of its dog-chain and, swinging inboard from the fore-gallows, had crushed the boatswain to a pulp.

26.758 c: \lobtagh \lobt-e3.h 85. [...] silo unloaders, feeders, side-unloading trailers and other associated equipment for the new techniques. But the material also handles well with a fore-loader, it is said, and has zero grazing possibilities as well. 
(13)

One-dimension patterns of contact.

E.g.: anteroom

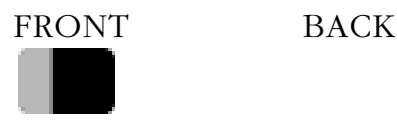

One-dimension patterns of partition (no contact)

\section{E.g.: forefinger}

\section{FRONT}

BACK
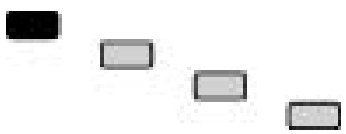

Two-dimension patterns. E.g.: fore-loader

FRONT

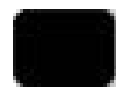

BACK

Three-dimension patterns. E.g. forehead, foreskin

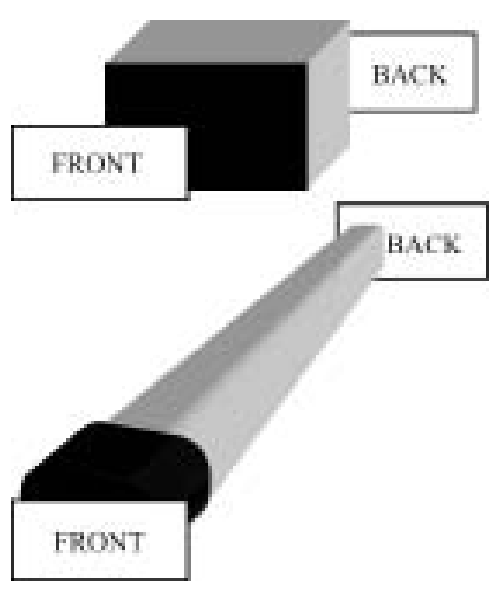

Dimensionality and Perspective in formations with the prefix fore\#. 
What we conclude from this analysis is that the typology of the entities and the semantic specifications entail experiential factors that should be considered as essential criteria in the description and interpretation of locative units. As illustrated above, these factors predict that, taking formations like foreroom, forefinger, foregallows, forehead and foreskin, all of them subsumed under the domain Spatial Anteriority, the unit foreroom will be associated to the lowest level within the domain, whereas forefinger, fore-gallows, forehead and foreskin will follow down as more complex configurations.

\section{LOCATIVE DIMENSIONS AND THE ROLE OF METAPHOR}

In the preceding sections, we argued that lexemes and their schemata are organized into domains on the basis of semantic-cognitive criteria and that locative conceptualisations are based on a part-whole, metonymic relation. We will now lay the emphasis on the fact that domains are in turn organized into hierarchies, and that metaphor constitutes one of the primary resources for lexical structuring at this level.

Locative domains instantiate Spatial, Temporal and/or Notional conceptualisations. We may thus state that Space, Time and Notion constitute dimensions, highlevel semantic-cognitive restrictions within Location (see Langacker 1987:149). Sosa (2004a: $373 \mathrm{ff}$ ) observes that domains prototypically associate to the spatial and the temporal dimensions and that the notional dimension emerges from projections or metaphorical mappings of the more basic spatio-temporal features. Below we illustrate this progression from spatial and temporal scenarios into notional conceptualisations as a rotation of a horizontal spatio-temporal axis towards a vertical notional axis:

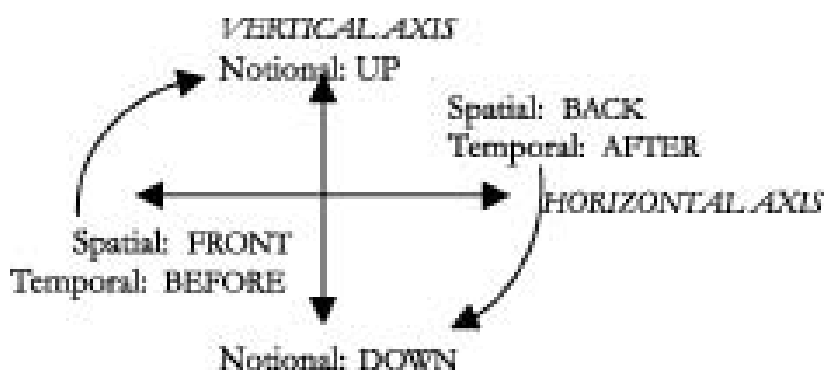

Rotation of axes and metaphorical projection, from space/time into notion. 
The rotation of the axes involves metaphorical processes through which inherent basic features of horizontal relations "are translated into" vertical interpretations: BEFORE becomes UP, AFTER becomes DOWN and the prepositional relations BEFORE/FRONT and AFTER/BACK become ON/OVER and BELOW/UNDER respectively (see Lakoff and Johnson 1980:14 ff.). Mappings of lexical features, however, seem to be deeply grounded not only in ontological factors (up, down, etc.), but also, and more significantly, in epistemic knowledge.

As an example, consider the form foreman. Svorou (1993: 74-75) claims that the experience of social relationships among human beings conforms to an anthropomorphic model of hierarchical categorisation. On the assumption that this model activates a general analogy between 'a man BEFORE a man' and 'a man ABOVE, at a higher position OVER a man', foreman may be interpreted as a part-whole relation in which man stands notionally, rather than physically, OVER a set of men (cf. forefinger). The orientational metaphor formulated by Lakoff and Johnson (1980: 15) as MORE IS UP gives way here to HAVING (more) CONTROL OR FORCE IS UP. In what follows, we shall show that the expansion of the metaphor MORE IS UP into chained metaphors like MORE IS UPÒ CONTROL IS UP in fact constitutes a recurrent device for the notional interpretation of spatio-temporal relations.

\section{METONYMY AND METAPHOR: THE CASE OF SUPERIORITY}

Thus far, the analysis of locative units suggests that there are two distinct, though interrelated, instruments, metonymy and metaphor, which are motivated by both ontological and epistemic knowledge and which operate at different levels of the semantic-cognitive structure of vocabulary: metonymy is essentially an intra-dimension phenomenon affecting the organization of lexemes into domains and subdomains, whereas metaphor is prototypically an inter-dimension device that motivates the expansion of basic spatio-temporal meaning (see Fernández Sánchez 1998):

\section{METONYMY}

Part: individual entity (man, finger...) Whole: set of individual entities (men, fingers...)

\begin{tabular}{l|l} 
Domains & Dimensions \\
\hline $\begin{array}{l}\text { foreroom } \\
\text { forefinger }\end{array}$ & Spatial \\
\hline foreman & Notional
\end{tabular}

\section{METAPHOR}

MORE IS UP

Dimensions

Spatial

Notional

Metonymy and metaphor in formations with the prefix fore\# 
One of the most interesting and clear instances of the role of metaphorical mappings is provided by the subdomain Anteriority $\rightarrow($ Distance $) \rightarrow$ Superiority. Formations of Superiority share a set of ontological and epistemic presuppositions associated to the concept of vertical parallelism. The two parallel entities are interpreted here as physical entities of the same typology that stand one over the other at a relative short distance in space, they never interact. However, the longer the physical distance between the entities, the higher the superiority of the upper over the lower and, not surprisingly, the longer the conceptual distance between the two. This view of parallelism as a process of gradual development articulates the whole domain of Superiority that comprises prototypical formations like foreman, supermarket, bypermarket, ultraviolet and exorbitant.

\section{FOREMAN}

As in the case of spatial and temporal scenarios (cf. anteroom, forefather, etc.), the participant entities in foreman are first-order entities (E.g: man in foreman). The specific relation they designate, however, is neither spatial nor temporal, but rather conceptual in nature: if first-order entities prototypically involve spatio-temporal relations (E.g: forefinger: 'finger BEFORE finger'), within the notional dimension, such entities are located on the vertical axis and designate 'entity $\mathrm{BEFORE} \rightarrow \mathrm{ON} / \mathrm{ABOVE} / \mathrm{BEYOND}$ entity' (E.g: foreman). These projections justify why the patterns underlying foreroom and foreman, which seem not to differ essentially from one another, are actually different in meaning, they belong in different dimensions. The subscript Notional Locus in the schemata below correspondingly indicates that foreman is interpreted as a notional formation in contrast to foreroom, forefinger, etc:

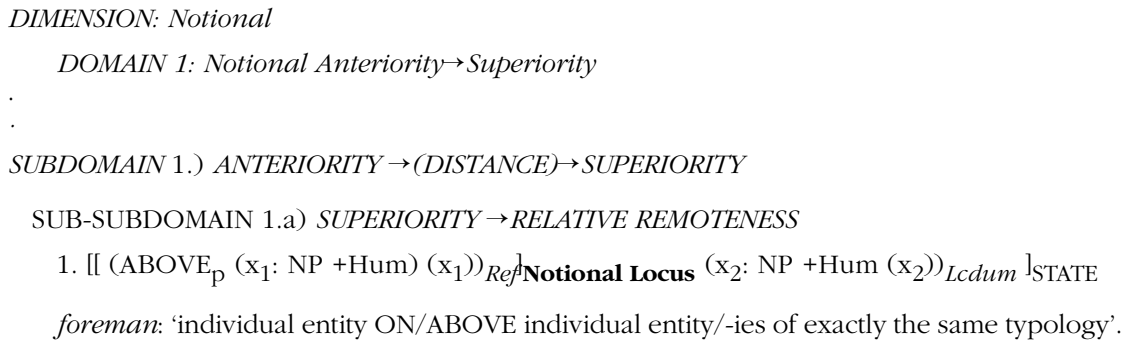




\section{SUPER/HYPERMARKET}

Both supermarket and bypermarket prototypically entail ontological properties related to the size and height of buildings. In bypermarket, one entity is conceptualised as being larger than (going beyond the limits of) another entity of the same typology (i.e. supermarket) which, in its turn, is larger than market. The formation bypermarket is thus construed on the basis of chained metonymies: ' bypermarket embeds supermarket that embeds market'.

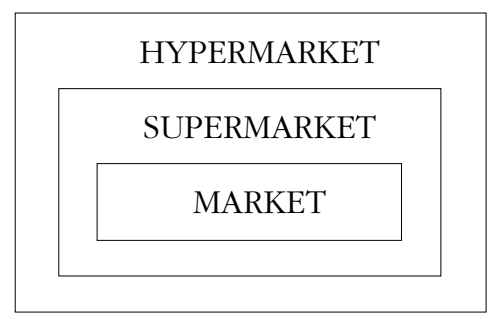

Conceptual image of chained metonymies in super/hypermarket.

Together with the physical interpretation of super/hypermarket as 'shopping place, building', however, there is a subtler, but socially rooted reading of these formations as the notional 'to go shopping'. The activity here substitutes for the object or place which, according to Lakoff and Johnson (1980:58-59) conforms to the ACTIVITY FOR OBJECT or PLACE metonymy. What is relevant about this metonymy is that, just as buildings are subject to gradation in size and height, once the activity 'shopping' replaces the object 'building', the former may be also subject to gradation, this time in amount and intensity: if ontological presuppositions based on size and height trigger degrees of physical superiority (i.e. hypermarket LARGER THAN supermarket LARGER THAN market), epistemic presuppositions related to 'shopping' give rise to degrees of superiority in amount or intensity (i.e. prototypically, the larger the object or place-shopping centre-, the larger the number of goods to buy - more intensive activity).

We will assume that the association of formations like hyper/supermarket to more than one dimension constitutes a case of conceptual polysemy (see Lakoff and Johnson 1980). Since these forms are related simultaneously to Space and Notion, we propose to regard them as part of a transitional dimension, the Spatial-Notional dimension (E.g. Spatial interpretation: They are building a new supermarket/ bypermarket in the city; Notional interpretation: The European supermarket/hypermarket of strawberry): 
(18)

\section{LOCATIVE SPATIAL/NOTIONAL DIMENSION}

1) SUPERIORITY

1.a) SUPERIORITY $\rightarrow$ INCLUSION

(A) DENOMINAL

1. [(OVER $\left.\rightarrow \mathrm{ON}_{\mathrm{p}}\left(\mathrm{x}_{1}: \mathrm{NP}+\mathrm{Sh},+\operatorname{Art}: \text { building }\left(\mathrm{x}_{1}\right)\right)_{R e}\right] \mathbf{s p a t}_{\mathbf{N}}$ Not.Locus $\left.\left(\mathrm{x}_{2}: \mathrm{NP}+\mathrm{Sh},+\operatorname{Art}: \text { building }\left(\mathrm{x}_{2}\right)\right)_{\text {Lcdum }}\right]_{\text {STATE }}$ supermarket (LOB) hypermarket

\section{ULTRAVIOLET}

Like super/bypermarket, ultraviolet designates a property that goes beyond the limits of the basic property violet (entity-Ref). If we assume that the spectrum of light is conceptualised as a set of parallel perceptual boundaries, ultraviolet is radiation that falls outside the range of perception within the spectrum, lying parallel to the upper borderline of violet. It thus conceptualises a relation between entities that still share basic properties (i.e. they are all light, just as market, supermarket and bypermarket are all buildings) but that differ dramatically with respect to conditions of visual perception:

(19)

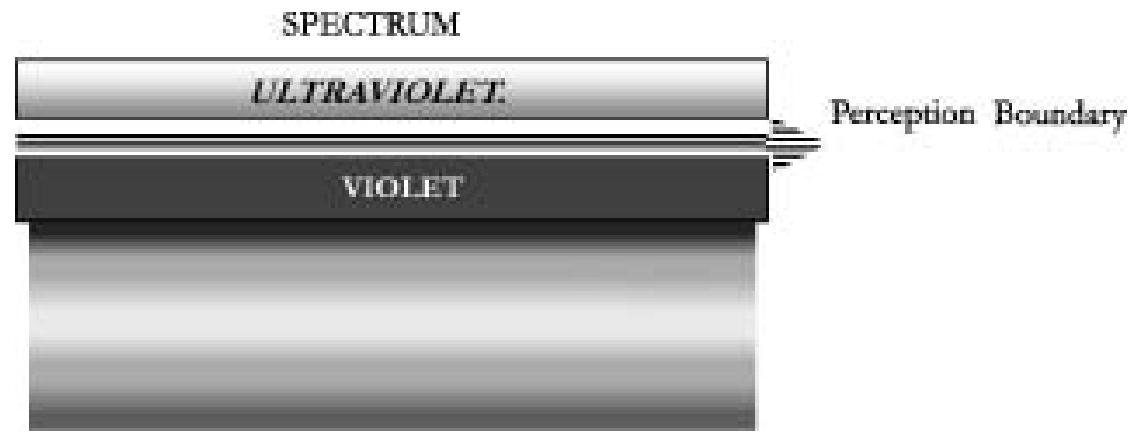

Conceptual image of Ultraviolet

EXORBITANT

Exorbitant expresses 'property of an entity BEYOND/OUTSIDE property of an entity'. Vertical parallelism here takes the form of concentric itineraries as a result of 
the circular shape of the orbit: 'circle around and OVER circle'. ${ }^{11}$ Like ultraviolet, exorbitant indicates that one of the entities goes beyond the other, that is to say, beyond the range of the orbit. However, while ultraviolet is still part of the spectrum, the entity characterized as exorbitant is conceptualised as being extremely distant from the orbit, no longer within its scope, and therefore, at a higher position from the Referent. It is precisely the presence of such epistemic presuppositions that allows for the metaphorical interpretation of this unit, widely spread in present-day English standards, as 'exaggeration, extreme degree of...' which seems to be based on the chained metaphor MORE IS UPÒ EXCESS IS ABOVE (E.g. exorbitant prices, fees, amounts...). The corresponding conceptual image may be represented as follows:

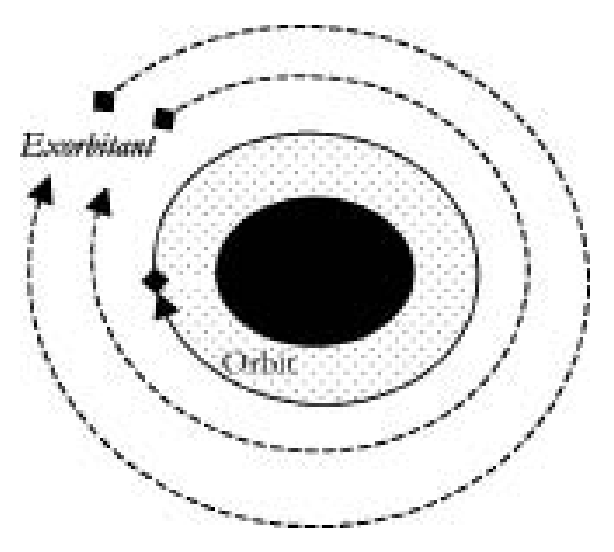

Conceptual image of vertical parallelism in concentric shape. E.g: . Exorbitant

The main conclusion to be drawn from this section is that the prefixes fore\#, super\#, byper\#, ultra\# and ex\# correlate with increasing degrees of superiority and constitute part of a continuum in which such degrees are viewed as progressive, rather than as clear-cut distinctions:

11. Concentric relations entail the basic ontological presuppositions of vertical parallelism, including the fact that the spatial scenario is categorised as a two-dimensional setting: trajectories describe itineraries with two ends, be they straight (E.g. horses running parallel in a horse race) or circular (E.g. planets moving parallel within the orbit). 
(21)

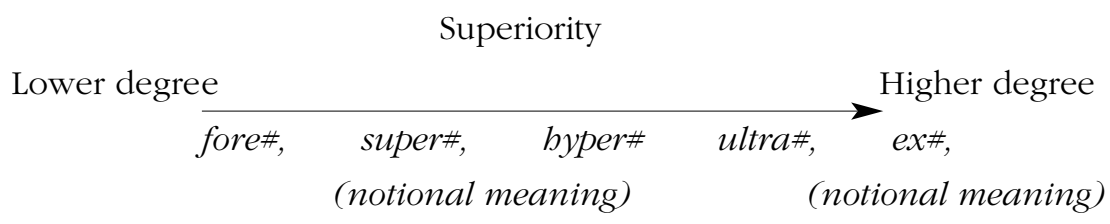

Furthermore, the existence of polysemous interpretations like super/ bypermarket indicates that there is also a dynamic transition of both ontological and epistemic information from domain to domain, and/or from dimension to dimension. Indeed, there seem to be no discrete borderlines within the whole macrostructure of the lexicon in which transitions even arise between apparently unconnected domains. Consider, for example, the domains Superiority and Movement (E.g. transplant 'movement of a plant from one place to another'). In some denominal formations of Movement like trans-sexuality, the entities are interpreted as being extremely separate, remote, no longer parallel, and a new metaphorical mapping from space into notion seems to operate: LOSING A PROPERTY IS GOING TOO FAR BEYOND THE STANDARD PROPERTY. By the action of this metaphor, trans-sexuality designates 'sexuality 2 FAR BEYOND/ REMOTE FROM/NO LONGER sexuality,', that is to say, going so much BEYOND the social standards of sexual identity means becoming a member of the opposite sex. Once again, this complex configuration embodies a chained metaphor. LOSS OF PROPERTY IS MOVEMENT AWAY FROM THE PROPERTY MOVEMENT AWAY FROM A PROPERTY IS CHANGE LOSS IS CHANGE:

\author{
Sexuality $_{2}$ (E.g Female/Male sex) \\ Trans-sexuality \\ Sexuality $_{1}$ (E.g Male/Female sex) \\ Transition from Superiority to Movement in Transexuality
}

\title{
7. CONCLUSION
}

Far beyond the formal properties of prefixed lexical units, there is sufficient evidence to believe that the underlying mechanisms of metonymy and metaphor consistently determine lexical structure. The functional-lexematic approach has been presented here as a powerful means to capture the role of these two complementary mechanisms. 
Through transformations like PFRs, morphological regularities are subject to insufficient restrictions at the same time that irregularities are given no adequate functional explanation.

Now, going back to (2) above, where we stated some of the weak points that PFRs show for an adequate treatment of derivation, we conclude that, first, ad hoc formations like, for instance, super-school, are motivated by the same presuppositions that generate prototypical formations of superiority. In particular, super-school could be interpreted metaphorically as 'school with ideal or optimum conditions to study' on the basis of the ACTIVITY FOR OBJECT metonymy that characterizes prototypical formations like supermarket in its notional interpretation ('larger market', 'more goods to buy'). Similarly, ?superfather or ?super-soul could be reinterpreted as novel formations that follow fixed derivational patterns (E.g. superman, super-ego: man/father, ego/soul OVER man/father, ego/ soul).

As for forefinger and byperactive, we may state that the motivations underlying these formations are the same that restrict *ultraman, *fore-active, *byper-see or *hypersupermarket. On the one hand, locative prefixes instantiate specific conceptual scenarios based on ontological and epistemic information. Thus, the prefix fore\# prototypically designates spatial or temporal conceptualisations of a physical entity and, for this reason, it adjoins nominal and verbal bases rather than adjectival forms (E.g. forefinger. 'finger BEFORE finger': 'first, more salient finger'; foresee: see (an entity) BEFORE see: 'see in advance'). In contrast, byper\# and ultra\# prototypically designate degrees of inherent properties with adjectival bases (E.g. byperactive: 'ACTIVE $\mathrm{PROPERTY}_{\mathrm{P}}$ in a high degree'). On the other hand, this division of labour gives rise to a hierarchy of lexemes and, in turn, to a hierarchy of domains and of dimensions that together constitute the lexical macrostructure. Since lexemes are onomasiologically organized, lower-level prefixes cannot combine with higherlevel prefixes on the same formation which explains why combinations like *superbypermarket would not be possible in English. Hence also, the distinction between foreman (man OVER man on a social scale) and superman (man OVER/BEYOND man on a notional scale), each of which designates specific degrees of superiority within the same domain. Finally, "transitional" formations like super/bypermarket or transexuality add to the evidence that location is conceptualised as a continuum and that metonymy, metaphor and polysemy cut across dimensions as a means to expand basic meaning.

As it was pointed out at the beginning of this paper, it has been our central concern to show that the functional-lexematic framework provides a fine-grained methodology that contributes to reinforce the functional perspective adopted by FG. 


\section{REFERENCES}

Aarts, J. M. C., and J. P. Calbert. 1979. Metaphor and Non-Metaphor (The Semantics of Adjective-Noun Combinations). Tübingen: Max Niemeyer Verlag.

Aronoff, M. 1985 (1976). Word Formation in Generative Grammar. Cambridge, Mass./London: The MIT Press.

Bally, Ch. 1950 (1932). Linguistique générale et linguistique française. Berne: Francke.

Cortés Rodríguez, F. J. 1996. Análisis lexemático-funcional de los adjetivos del campo de percepciones gustativas y olfativas en inglés y español. PhD Dissertation. University of La Laguna.

—. 1997a. "La morfología derivativa en la gramática funcional de Dik. ¿Formación de palabras o formación de predicados?". Alfinge (9): 119-134.

—. 1997b. "Lexicismo, modularidad y formación de palabras: la morfología generativa en los últimos veinte años del generativismo“. Miscelánea (18): 21-41.

—. 1997c. La creación léxica. Una aproximación funcional. La Laguna: Servicio de publicaciones de la Universidad de La Laguna.

Coseriu, E. 1986 (1981). Principios de semántica estructural. Madrid: Gredos.

De Groot, C. 1987. "Predicate Formation in Functional Grammar". University of Amsterdam. Working Papers in Functional Grammar (20).

- 1989. Predicate Structure in a Functional Grammar of Hungarian. Dordrecht-Holland/Providence RI, U.S.A: Foris.

Dik, S. C. 1997 (1989). The Theory of Functional Grammar. Part I: The Structure of the Clause. Dordrecht, Holland/Providence RI, U.S.A: Foris.

Faber, P. 1991. "The relational Structure of the lexicon: Its application to the field of sound verbs". Actas del XV Congreso de AEDEAN. Eds. Ruiz de Mendoza, F., and C. Cunchillos Jaime. Logroño: Colegio Universitario de La Rioja. 351-361.

Faber, P., and R. Mairal Usón. 1994. "Methodological underpinnings for the construction of a functional lexicological model". Miscelánea. A journal of English and American Studies 15: 19-217.

-. 1997a. "The syntagmatic and paradigmatic structure of the lexical field of EXISTENCE in the elaboration of a semantic macronet". Studies in Language (21,1): 119-154.

—. 1997b. "Definitional analysis in the Functional Lexematic Lexicographic Model". Alfinge (9): 219-232.

- 1998."Towards a typology of predicate schemata in a Functional Lexematic Model". Towards a Functional Lexicology. Ed. Wotjak, G. Frankfurt: Peter Lang. 11-37. 
—. 1999. Constructing a Lexicon of English Verbs. Berlin-New York: Mouton de Gruyter.

Fernández Sánchez, E. 1998. "Cognitive abilities for a functional-lexematic perspective". The structure of the lexicon in Functional Grammar. Eds. Olbertz, H., K. Hengeveld, and J. Sánchez García. Amsterdam/ Philadelphia: John Benjamins. 65-84.

Hengeveld, K. 1992. Non-verbal Predication. Theory, Typology, Diachrony. Berlin/New York: Mouton de Gruyter.

Johansson, S., E. Atwell, R. Garside, and G. Leech, eds. 1986. The Tagged LOB Corpus. Bergen: Norwegian Computing Centre for the Humanities.

Kristoffersen, L. 1991. Verbal Derivation and Inflection in a Functional Grammar of West Greenlandic. Tesis Doctoral. Univ. of Copenhaguen.

Lakoff, G., and M. Johnson. 1980. Metaphors We Live By. Chicago: Univ. of Chicago Press.

Langacker, R. 1987. Foundations of Cognitive Grammar. vol. 1. Standford: Standford U.P.

Mackenzie, J. L. 1986. "English Spatial Prepositions in Functional Grammar". University of Amsterdam. Working Papers in Functional Grammar (46).

- 1992. "Aspects of nominalization in English and Dutch". University of Amsterdam. Working Papers in Functional Grammar (15).

Mairal Usón, R. 1999. "El componente lexicón en la Gramática Funcional”. Nuevas perspectivas en Gramática Funcional. Eds. Butler, C., R. Mairal Usón, J. Martín Arista, and F. J. Ruíz de Mendoza. Barcelona: Ariel. 41-98

Marchand, H. 1969. The Categories and Types of Present-Day English Word Formation. A Synchronic-Diachronic Approach. München: C.H. Beck'sche Verlagsbuchhandlung.

Martín Mingorance, L. 1984. "Lexical fields and stepwise lexical decomposition in a contrastive English-Spanich verb valency dictionary". LEX'eter"83: Proceedings of the International Conference on Lexicography. Eds. Hartmann, R. Tubinga: Niemeyer.226-236.

—. 1985a. "La semántica sintagmática del adjetivo. Parámetros para la realización de un lexicón inglés-español de valencias adjetivales". Actas del Segundo Congreso Nacional de la Asociación Española de Lingüistica Aplicada. Ed. Monroy Casas, R. Madrid: Sociedad General Española de Librería. 329-340.

—. 1985b. "Bases metodológicas para un estudio contrastivo del léxico derivado." Revista Española de Lingüística Aplicada (1): 37-54.

-. 1987a "Classematics in a Functional-Lexematic Grammar of English." Proceedings of the Tenth National Congress of AEDEAN. 377-382. 
—. 1987b "Semes, semantic classemes, and dimensions: the lexicological and lexicographic perspectives". El Modelo lexemático-Funcional: El legado de Leocadio Martín Mingorance. Ed. Marín Rubiales, A. Granada: Servicio de Publicaciones de la Univ. de Granada. 209-224.

-. 1990. "Functional Grammar and Lexematics in Lexicography". El Modelo lexemático-Funcional: El legado de Leocadio Martín Mingorance. Ed. Marín Rubiales, A. Granada: Servicio de Publicaciones de la Univ. de Granada. 101-132. Pustejovsky, J. 1998. The Generative Lexicon. Cambridge, Massachusetts: MIT Press.

Rosch, E. 1978. "Principles of categorization". Cognition and Categorization. Eds. Rosch, E., and B. B. Lloyd. Hillsdale: N.J. Erlbaum. 27-48.

Simpson, J., and E. Weiner, eds. 1989. The Oxford English Dictionary. $2^{\text {nd }}$ Edition. U.K: Oxford University Press.

Sinclair, J. 1995. The Collins COBUILD English Dictionary. London: Harper-Collins Publishers.

Sosa Acevedo, E. 2004a. Análisis funcional cognitivo de los procedimientos de prefijación locativa en inglés. Universidad de La Laguna: Servicio de publicaciones.

—. 2004b. "Semantic motivation and morphophonological features in English locative prefixation". Traditions and Innovations. Commemorating Forty Years of English Studies at ULL (1963-2003). Eds. Brito, M., and J. I. Oliva. La Laguna: RCEI. 157-166.

Spencer, A. 1988. "Bracketing paradoxes and the English lexicon". Language (64): 663-682.

Summers, D. ed. 1995. The Longman Dictionary of Contemporary English. $3^{\text {rd }}$ Edition. Harlow.

Svorou, S. 1993. The Grammar of Space. Amsterdam/Philadelphia: John Benjamins. 